\title{
Brandt iH026a plant growth regulator
}

\author{
A.M. NONOMURA ${ }^{*+}$, A. PEDERSEN ${ }^{* *}$, D.P. BRUMMEL ${ }^{* * *}$, L. LOVELESS ${ }^{\#}$, A. LAURIA ${ }^{\#}$ \\ B. HASCHEMEYER ${ }^{\#}$, and M.S. McBRIDE*
}

Carbon Reactions of Photosynthesis Sector, BRANDT iHammer, 479 Village Park Drive, Powell OH USA 43065-9178*

Department of Agronomy of Iowa State University, 2104 Agronomy Hall, Ames, IA, USA 50011-1010**

Brandt Consolidated, Inc., 3654 South Willow Ave., PO Box 35000, Fresno CA USA $93725^{* * *}$

Brandt Consolidated, Inc., 2935 S. Koke Mill Road, Springfield, IL USA 62711-9561"

\begin{abstract}
$\mathrm{iH} 026 \mathrm{a}$ is a formulation containing a biochemical class of plant growth regulator that modulates glycoconjugation through the plant lectin cycle. While lectins are common to vascular plants, we observed, consistent with reversible binding of sugars from lectins, enhancements of quantities and qualities of various features, including significant enrichment of Brix soluble sugars compared to controls in cherry, grape, and melon in trials conducted in Arizona and California, USA.
\end{abstract}

Additional key words: agriculture; glycoside; Govindjee; plant growth regulator; photosynthate; respiration; Z-scheme.

\section{Foreword}

Integral to the whole of his academic expertise in plant sciences, Govindjee has been connected with agricultural concerns including chemical companies that have benefited in a scholarly manner from keeping up to date on advances in photosynthesis. In the course of development, various industries have been in consultation with Govindjee for his keen understanding of the flow of energy into the light reactions and on to the carbon reactions of photosynthesis (CROP). In 2014, coauthors Nonomura and McBride instituted the transfer of some concepts of photosynthesis to agriculture with the founding of Brandt iHammer; and they initiated a collaborative effort with Govindjee to further distribute his educational materials, especially his posters depicting the Z-scheme. In the course of over half a century, updates to Z-schemes were driven by discoveries (Govindjee 2017). In fact, three different Z-schemes are exhibited in Fig. 1, as follow: On the wall behind McBride hangs an original Z-scheme from 1964, hand-drawn by Govindjee and University of Illinois botanical artist, Natalie Davis; to the far right front, Govindjee signed his 1990's version; and all while, McBride held the current Z-scheme.

Fortunately, the headquarters of the parent company, Brandt Consolidated, are located in Springfield, IL, and agricultural relations with University of Illinois have a history of over 60 years of innovation in the field. Energetic discussions with Govindjee will continue to contribute to improving the transfer of scientific methods to agriculture, challenging as that may be; and the plant scientists as well as CROP specialists at Brandt Consolidated and Brandt iHammer regard Govindjee, gentleman and great scientist, with highest honor. We look forward to a sweet future with Govindjee as he stays on the cutting edge of science.

Happy Birthday, Govindjee!

\section{Introduction}

We have given our attention to previous investigations that have shown beneficial responses of a broad scope of plant species to treatments with formulations of alkylglycosides (e.g., Benson et al. 2009) as our interests are in the successful link to regulation of the carbon reactions of photosynthesis (Biel and Fomina 2015). Of particular impact, following the path of radiolabelled methyl- $3-D-$ glucopyranoside (MeG) in plants (Biel et al. 2010)

Received 16 February 2017, accepted 3 May 2017, published as online-first 13 June 2017.

${ }^{+}$Corresponding author; phone: +1(623)2255278, e-mail: Art.N@BRANDTiHammer.co

Abbreviations: $\alpha \mathrm{MN}-\alpha$-mannoside; ANOVA - analyses of variance; CROP - carbon reactions of photosynthesis; MeG - methyl- $\beta-\mathrm{D}-$ glucopyranoside; PGR - plant growth regulator; 95CI - 95\% confidence interval; UTC - untreated control.

Acknowledgements: We are thankful to The Brandt Family for supporting field confirmations of the PGR activity of iH026a; to Cody Parker for extraordinary expertise in crop management; and United States patents 8093182, 9072304 and 9277697.

(C) The Author(s). This article is published with open access at link.springer.com 




Fig. 1. During a visit with Govindjee (right), in his office at the University of Illinois, co-author McBride gained a deeper understanding of cutting-edge details of the Z-scheme in 2016 and, as well, became the recipient of autographed posters. Displayed on the left wall, an original Z-scheme hand-drawn by Govindjee in 1964; to the right, Govindjee signed his 1990's version; while McBride studied the current Z-scheme (Govindjee et al. 2017).

contributed to our understanding of durational effects that characterized a certain practicality for agriculture. Since 2014, Brandt Consolidated formed a joint venture with Brandt iHammer to develop commercial products for sports turf based on earlier experiments with grass and formulations of glycosides (Nonomura and Benson 2012). Recognition of the plant lectin cycle (Nonomura and Benson 2014) led to the transfer of CROP-based technologies to field applications and, thereafter, to the plant growth regulator (PGR)-formulation of choice for current investigations with iH026a. The mechanism of action of iH026a, modulation of glycoconjugation (Biel and Fomina 2015, Fomina and Biel 2016), is based on the ubiquitous presence of lectins in species of the plant kingdom and photosynthetic protistans.

\section{Materials and methods}

Experiments with various farm cultivars were conducted from 2013 through 2015 in field research plots from Arizona and California, USA. Control plots were in the same fields as treated plots and, therefore, all plots were cultivated according to the same growers' standard except for foliar treatments with iH026a; and, thus, controls without the experimental treatments are abbreviated, UTC. Treatments were applied in an effective dose range of $0.1-$ $1.5 \mathrm{~L}$ (iH026a) ha $\mathrm{ha}^{-1}$ and were applied either once per season or at 2 to 4 week intervals. The iH026a product formulation containing the active $\alpha \mathrm{MN}$ ingredient was obtained from Brandt iHammer. Brix, a measure of soluble sugar $\%$
The plant lectin cycle presents a metabolic pathway for reversible conjugation of photosynthates in vacuolar lectins (Nonomura and Benson 2014). Not only do these abundant lectin complexes bind and store mono- and oligosaccharide photosynthates, but also they release them (e.g., Lanoo et al. 2007), particularly when displaced by exogenous compounds that chemically compete for the same sites. Indeed, the term, lectin, has the same root, meaning to choose, in "select" and "elect"; and based on chemical competition for glycoconjugation sites, certain compounds may "elect" whether to bind or release from lectins. Thus, compounds selected for higher binding affinities and higher binding specificities than photosynthates of lower binding tendencies to lectins may be applied to plants to displace them. After field treatments, photosynthates, thus released, may be transported to roots and shoots (Biel et al. 2010, Nonomura et al. 2011, Nonomura et al. 2012). As a consequence, flavor components, mainly sugars, may accumulate and enhance qualities of harvests. Elucidation of mechanisms based on the plant lectin cycle laid the foundation for the development of agricultural formulations that showed potential to enhance crops by treatment with exogenous glycoconjugates; and, therefore, for his discoveries of metabolic pathways, the late Andrew A. Benson received the eponymous award from Brandt iHammer for benefitting mankind through modulation of glycoconjugation (Lichtenthaler et al. 2015, Nonomura et al. 2016).

As candidates for development of PGRs, such as the current iH026a product formulation, Nonomura and Benson $(2013,2014)$ had identified $\alpha$-mannoside $(\alpha M N)$ compounds of higher potencies than MeG. The extent of their strengths in the field corresponded to the order of their respective lectin-binding affinities. In our current field investigations, we conclude that, consistent with methods for modulation of glycoconjugation, our applications of $\mathrm{iH} 026 \mathrm{a}$ to crops resulted in general increases of soluble sugars contents of fruits as compared to controls.

content, was analyzed with a Reichert digital refractometer. The soluble sugars mass fraction of the harvest yield was the product of Brix multiplied times the total harvest mass. Data analyses compared mean values, SD and SE for different treatments ( $t$-test, significant at $p \leq 0.05)$, and in graphs $\pm 95 \mathrm{CI}$ for which mean is the center point. Software included IBM ${ }^{\circledR}$ SPSS ${ }^{\circledR}$ Statistics Premium (www.spss.com); Microsoft Excel; and Agriculture Research Manager 2016, Gylling Data Management, Inc., used for data management, crop production experiments and analysis of variance $(A N O V A)$ by field researchers. 
Melons: Field confirmations of the efficacy of iH026a PGR were conducted on Citrullus lanatus (Thunb.) Matsum. \& Nakai fall watermelons in 2013; and Cucumis melo var. cantalupo Naudin cantaloupe melon in 2013 and 2014. Exploratory melon trials on side-by-side $15.2 \mathrm{~m}$ rows were initiated without replicates in 2013, in Roseboro, NC, USA (LL Corner: $34.88197^{\circ} \mathrm{N}$; $\left.78.5690556^{\circ} \mathrm{W}\right)$. Melons for 2013 trials were given foliar applications of $1.46 \mathrm{~L}(\mathrm{iH} 026 \mathrm{a}) \mathrm{ha}^{-1}$, in volumes of $468 \mathrm{~L}$ $\mathrm{ha}^{-1}$. Treatments were initiated at first bloom, followed by weekly foliar sprays for a total of four applications. The fall 2013 cantaloupes were harvested, weighed, and Brix was measured on 17 October 2013. Fall watermelons were treated similarly, but harvested on 23 October 2013. In both of these early field trials, melons, which were treated with iH026a, showed enhanced Brix and fresh mass yields that provided the basis for further field investigations of cantaloupes, as follows.

Replicated melon trials were undertaken from 1 April to 4 June 2014 , in a drip-irrigated system on a farm in Tonopah, Maricopa County, Arizona, USA (LL Corner: $33.370423^{\circ} \mathrm{N}, 113.203027^{\circ} \mathrm{W}$ ). Soil was analyzed as Laveen loam, comprised of sand $43 \%$; organic matter of $0.65 \%$; clay of $17.5 \%$; $\mathrm{pH} 8.2$; conventional tillage. Plants were machine transplanted into beds lined with plastic. These trials were randomized complete block design with four replicates in $3 \mathrm{~m} \times 0.2 \mathrm{~m}$ plots containing seven plants each, flagged to identify treatments and map locations for recording observations. These trials included the UTC and foliar applications of $0.48 \mathrm{~L}$ (iH026a) ha ${ }^{-1}$. In 2014, two foliar applications of $\mathrm{iH} 026 \mathrm{a}$ were made to each treated plot. The first application on 1 April 2014 was at early bloom when plants had 5-6 fully expanded leaves. The second application, on 20 May 2014, was made two weeks prior to picking. For foliar treatment, $0.03 \%$ Brandt ${ }^{\circledR}$ Super Wetter organo-modified siloxane was added to each of the tank mix solutions. Foliar applications were made with a $\mathrm{CO}_{2}$-pressurized backpack sprayer. The first application was made with a 2-nozzle spray boom at a foliar application volume of $280 \mathrm{~L} \mathrm{ha}^{-1}$. The second application was made with a 3-nozzle spray boom at a volume of $468 \mathrm{~L} \mathrm{ha}^{-1}$. Fruit evaluation was conducted on 4 June 2014. In each plot, six fruits deemed sufficiently mature and large to harvest were hand-picked and immediately weighed in the field using a spring scale. Later that same day, the juice from each harvested fruit was analyzed for Brix.

Grapes: Field experiments on Vitis sp. "DOVine" variety of raisin grapes were conducted from 24 June to 6 August 2015, in a drip-irrigated vineyard in Kettlemen City, Kings County, California, USA (LL Corner: $35.873879^{\circ} \mathrm{N}$; $\left.119.846597^{\circ} \mathrm{W}\right)$. Grapes were grown on cane-pruned overhead trellis systems and with six replications. Vines were in 3.4-m row spacing and $1.2 \mathrm{~m}$ between vines. As an effective spreader, penetrant, deposition aid, and acidifier, $0.12 \%$ Brandt ${ }^{\circledR}$ Super 7 alcohol ethoxylate, lecithin, propionic acid, was added to each of the tank mix solutions. Applications to the entire fruit and foliage of the vines were by a Stihl SR420 mist blower, adjusted for application of a mist to the shoots at a volume of $935 \mathrm{~L} \mathrm{ha}^{-1}$. Each plot included two consecutive vines from two adjacent rows for a total of four vines per plot. This experiment had three different treatments, including one untreated control and the two doses, 0.77 and 1.5 $\mathrm{L}(\mathrm{iH} 026 \mathrm{a}) \mathrm{ha}^{-1}$, that were applied. Initial treatments were applied at early verasion on 24 June 2015; and the second treatments were applied on 9 July 2015. Harvests were undertaken on 5 August 2015. From the center of each plot, 12 average bunches were selected at random. Fresh masses of all 12 bunches were taken in field immediately after picking. From each harvested bunch, 18 berries were picked and the juices from the berries were analyzed for Brix content of soluble sugars.

Fruit data from each rate of $\mathrm{iH} 026 \mathrm{a}$ were analyzed individually for comparisons against UTC. The trial was conducted on a raisin variety, therefore, final dry masses were estimated using a raisin drying ratio of the estimated dry mass of 12 bunches per plot from Christensen and Peacock (2000) as follows:

$$
\mathrm{R}=13.2986-0.8550 \mathrm{~B}+0.02803 \mathrm{~B}^{2}-0.0004052 \mathrm{~B}^{3} \text {; }
$$

where $\mathrm{R}$ - fresh mass to dry mass ratio, B - Brix [\%] of fruit at harvest.

Cherry: Field experiments on Prunus avium L., Rainier sweet cherry, were conducted on a drip-irrigated field in Tulare, Tulare County, California, USA (LL Corner: $\left.36.210345^{\circ} \mathrm{N}, 119.288738^{\circ} \mathrm{W}\right)$. Plot size adopted for the experiment was 6-m row width and $5.2 \mathrm{~m}$ between trees, rows oriented E-W, and in four-replicate randomized complete block design with one tree in each plot. There were five treatments in the trial including two UTC. To each of these applications, $0.12 \%$ Brandt ${ }^{\circledR}$ Super 7 was added to the tank mix solutions. All applications were made as broadcast foliar sprays with a Stihl SR420 mist blower at a volume of $935 \mathrm{~L} \mathrm{ha}^{-1}$. This trial was a continuation of treatments from the 2014 season and the same cherry trees were treated with a program of three applications in 2015. In 2014, there were two in-season applications and one post-harvest application. Initial applications of $0.19 \mathrm{~L}(\mathrm{iH} 026 \mathrm{a}) \mathrm{ha}^{-1}$ were made on 8 April and 9 May 2014; and 0.38 and $0.77 \mathrm{~L}(\mathrm{iH} 026 \mathrm{a}) \mathrm{ha}^{-1}$ on 15 October 2014. The first $0.77 \mathrm{~L}(\mathrm{iH} 026 \mathrm{a}) \mathrm{ha}^{-1}$ application of 2015 was made at petal fall on 24 March 2015, the second during green fruit sizing on 7 April 2015, and the third at color initiation on 27 April 2015.

At bloom, ten fruiting branches were flagged on each tree; five on the north side, and five on the south side. Blossoms were counted at this blooming stage. Plots were evaluated once by picking 100 fully colored fruit from each plot on 4 May 2015. All 100 fruits were weighed later the same day on an Ohaus Scout Pro digital balance. The number of colored fruits per tree was counted. The 
estimated fruit mass at picking was calculated using the mean fruit mass and the count per tree. The juices of 10

\section{Results}

Melon: Our exploratory field trials from 2013 provided some guidelines for enhancing qualities and quantities of crops after treatment with $1.46 \mathrm{~L}(\mathrm{iH} 026 \mathrm{a}) \mathrm{ha}^{-1}$. That is, fall 2013 watermelons showed UTC of $47,128 \mathrm{~kg} \mathrm{ha}^{-1}$ estimated yields, as compared to those treated with iH026a that resulted in $58,015 \mathrm{~kg} \mathrm{ha}^{-1}$ estimated yields. Similarly, fall 2013 cantaloupes showed control yield of $289,013 \mathrm{~kg}$ $\mathrm{ha}^{-1}$ as compared to cantaloupes treated with iH026a that showed an increase to $383,762 \mathrm{~kg} \mathrm{ha}^{-1}$ estimated yields. In both exploratory trials, soluble sugar enhancements after treatments with iH026a showed cantaloupe Brix 9.6\%, and watermelon Brix $10.73 \%$ as compared to UTC cantaloupe Brix 8.5\%, and UTC watermelon Brix 10.15\%.

Based on these initial observations suggesting that treatments with iH026a may improve flavor qualities and mass quantities of melons, we decided to pursue replicated field trials on cantaloupe for 2014. Our statistical summary of Brix, Table 1, showed significant enhancement of sweetness in cantaloupe treated with $0.48 \mathrm{~L}(\mathrm{iH} 026 \mathrm{a}) \mathrm{ha}^{-1}$, as compared to UTC, in 2014. This enhancement of fruit flavor quality is further summarized in Fig. 2, in which mean is the center point of 95CI bar exhibiting iH026a mean Brix $13.9 \%$ soluble sugars content that was higher than control mean Brix 12.8\% content.

Table 1. Comparison of means indicates statistically significant enhancement of Brix of cantaloupe fruit after treatment with $0.48 \mathrm{~L}$ (iH026a) ha ${ }^{-1}$, as compared to UTC. $p=0.008$.

\begin{tabular}{lllll}
\hline Treatment & $n$ & Mean Brix & SD & SE \\
\hline UTC & 24 & 12.8 & 1.67 & 0.34 \\
iH026a & 23 & 13.9 & 1.12 & 0.23 \\
\hline
\end{tabular}

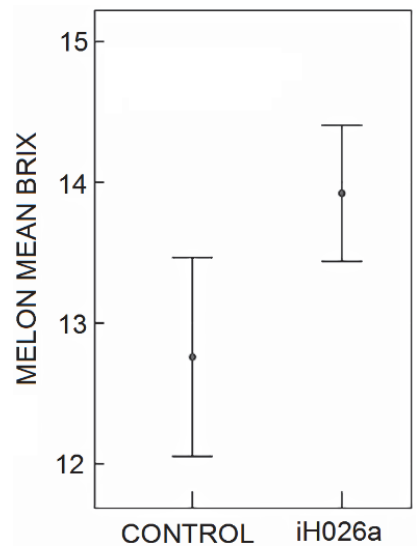

Fig. 2. Effect of foliar treatments of cantaloupe with 0.48 L(iH026a) ha $\mathrm{ha}^{-1}$ showed significantly higher Brix $13.9 \%$, as compared to control Brix 12.8\%. $n=4, \mathrm{SD}=0.020 ;$ ANOVA Student-Newman-Keul's test, $p$-value 0.05 . fruits per plot were individually analyzed the next day to determine Brix.

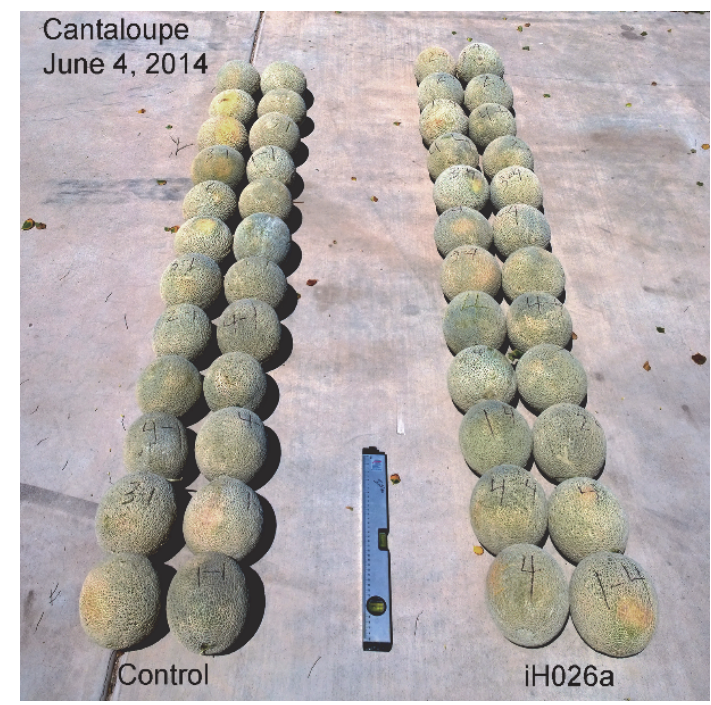

Fig. 3. After harvesting cantaloupes from field trials in Arizona, 2014, the melons were lined-up. To our surprise, the statistically significant differences between control mean of $2 \mathrm{~kg}$ per fruit (left of $40-\mathrm{cm}$ scale bar) and treatment with foliar $0.48 \mathrm{~L}(\mathrm{iH} 026 \mathrm{a}) \mathrm{ha}^{-}$ ${ }^{1}$ mean of $2.2 \mathrm{~kg}$ per fruit cantaloupe (right) also were visibly perceptible.

Treatment of cantaloupes with iH026a resulted in significantly enhanced mean mass of each cantaloupe fruit to $2.2 \mathrm{~kg}$ per fruit as compared to UTC with $2 \mathrm{~kg}$ per fruit. Moreover, in the visual comparison displayed in Fig. 3, treatment with foliar $0.48 \mathrm{~L}(\mathrm{iH} 026 \mathrm{a}) \mathrm{ha}^{-1}$ showed discernibly larger cantaloupe than control fruits.

Calculation of the soluble sugars mass fraction of the harvest yield after treatment with $0.48 \mathrm{~L}(\mathrm{iH} 026 \mathrm{a}) \mathrm{ha}^{-1}$ resulted in $0.31 \mathrm{~kg}$ (soluble sugars) per melon, an enhancement as compared to the UTC of $0.26 \mathrm{~kg}$ (soluble sugars) per melon. Therefore, treatment of melons with $0.48 \mathrm{~L}$ (iH026a) ha ${ }^{-1}$ improved both fruit flavor quality and sugar quantity.

Grape: Foliar treatment of raisin grape vines with iH026a showed statistically significant increases of soluble sugar content as compared to control. Means were compared by paired two-sample $t$-test in which raisin grape plots treated with $1.5 \mathrm{~L}(\mathrm{iH} 026 \mathrm{a}) \mathrm{ha}^{-1}$ showed significantly higher mean Brix $20.7 \%$ as compared to UTC mean Brix 18.7\%. In contrast, treatment with $0.77 \mathrm{~L}(\mathrm{iH} 026 \mathrm{a}) \mathrm{ha}^{-1}$ resulted in mean Brix 20.1\% soluble sugars content that was not significantly different from that of UTC.

Treatments of raisin grapes at $0.77 \mathrm{~L}(\mathrm{iH} 026 \mathrm{a}) \mathrm{ha}^{-1}$ resulted in significantly greater fresh mean $6.5 \mathrm{~kg}$ per 12 bunch as compared to UTC fresh mean of $6.1 \mathrm{~kg}$ per $12-$ bunch; and significantly higher estimated dry mean of 
$1.6 \mathrm{~kg}$ per12-bunch than UTC estimated dry mean of 1.4 $\mathrm{kg}$ per 12-bunch. In contrast, estimated mean dry masses after treatment with $1.5 \mathrm{~L}(\mathrm{iH} 026 \mathrm{a}) \mathrm{ha}^{-1}$ of $1.5 \mathrm{~kg}$ per12bunch (SD 0.30, SE 0.12) were not significantly different $(p=0.17)$ from UTC estimated mean dry mass of $1.4 \mathrm{~kg}$ per 12-bunch (SD 0.12, SE 0.05).

Calculation of the soluble sugar fraction of the harvest yield after treatment with $0.77 \mathrm{~L}(\mathrm{iH} 026 \mathrm{a}) \mathrm{ha}^{-1}$ resulted in $0.32 \mathrm{~kg}$ (soluble sugars) per 12-bunch; treatment with 1.5 $\mathrm{L}$ (iH026a) ha ${ }^{-1}$ resulted in $0.31 \mathrm{~kg}$ (soluble sugars) per 12bunch; and treatments with either dose resulted in enhancements of the soluble sugar fraction of the harvest yield as compared to the UTC of $0.26 \mathrm{~kg}$ (soluble sugars) per 12-bunch, as shown in Table 2.

Table 2. Treatments of raisin grape vines with 1.5 or 0.77 $\mathrm{L}$ (iH026a) ha $\mathrm{h}^{-1}$ resulted in different mean Brix per 12-bunch and total mean yields per 12-bunch as compared to UTC. However, the soluble sugar fraction of the total yield in $\mathrm{kg}$ per 12-bunch estimated mean dry mass harvest was similarly enhanced by either dose of treatments with iH026a as compared to UTC.

\begin{tabular}{|c|c|c|c|c|c|c|}
\hline Treatment & $n$ & Brix $[\%]$ & & SD & SE & $\begin{array}{l}\text { Sugar fraction } \\
{[\mathrm{kg}]}\end{array}$ \\
\hline UTC & 6 & 18.7 & & 1.54 & 0.63 & 0.26 \\
\hline $\begin{array}{l}\text { iH026a } \\
077 \mathrm{ha}^{-1}\end{array}$ & 6 & 20.7 & 0.02 & 2.36 & 0.97 & 0.32 \\
\hline $\begin{array}{l}\text { iH026a } \\
1.5 \mathrm{~L} \mathrm{ha}^{-1}\end{array}$ & 6 & 20.1 & 0.09 & 1.54 & 0.63 & 0.31 \\
\hline \multicolumn{7}{|c|}{ Total yield [dry kg] } \\
\hline UTC & 6 & 1.4 & & 0.12 & 0.05 & \\
\hline $\begin{array}{l}\text { iH026a } \\
0.77 \mathrm{~L} \mathrm{ha}^{-1}\end{array}$ & 6 & 1.6 & 0.02 & 0.19 & 0.08 & \\
\hline $\begin{array}{l}\text { iH026a } \\
1.5 \mathrm{~L} \mathrm{ha}^{-1}\end{array}$ & 6 & 1.5 & 0.17 & 0.30 & 0.12 & \\
\hline \multicolumn{7}{|c|}{ Total yield [wet kg] } \\
\hline UTC & 6 & 6.1 & & 0.37 & 0.15 & \\
\hline $\begin{array}{l}\text { iH026a } \\
0.77 \mathrm{~L} \mathrm{ha}^{-1}\end{array}$ & 6 & 6.5 & 0.04 & 0.70 & 0.29 & \\
\hline
\end{tabular}

Cherry: Our statistical summary of cherry measurements, (Table 3) showed significant enhancement of sweetness, flowering, and yields after treatment with $0.77 \mathrm{~L}$ (iH026a) $\mathrm{ha}^{-1}$ as compared to UTC. Measurements of cherries analyzed for soluble sugars on 5 and 12 May showed significantly enhanced fruit mean Brix $19.8 \%$ after treatment with $0.77 \mathrm{~L}(\mathrm{iH} 026 \mathrm{a}) \mathrm{ha}^{-1}$ as compared to UTC mean Brix $18.6 \%$. These differences in sweetness of treated cherries as compared to UTC are graphically summarized in Fig. 4.

Cherry trees treated with 0.77 L(iH026a) ha ${ }^{-1}$ showed significantly higher mean flower 78 count than UTC mean count of 58 flowers from 24 March; and, again, treatment with iH026a showing significantly higher mean 137 flower count as compared to UTC 120 mean flower count on 17 April; and these comparisons of cherry blossoms are graphically summarized in Fig. 5.
Table 3. Treatments of cherry trees with $0.77 \mathrm{~L}(\mathrm{iH} 026 \mathrm{a}) \mathrm{ha}^{-1}$ resulted in significantly improved Brix, flower counts, fruit count and estimated weight yields as compared to UTC.

\begin{tabular}{lcllll}
\hline Treatment & $n$ & \multicolumn{2}{l}{ Brix [\%] $p$} & SD & SE \\
\hline UTC & 8 & 18.6 & & 0.54 & 0.19 \\
iH026a & 8 & 19.8 & 0.014 & 1.14 & 0.4 \\
0.77 L ha ${ }^{-1}$ & & & & & \\
March Flower [count] & & & & \\
UTC & 4 & 58 & & 8.3 & 4.2 \\
iH026a & 4 & 78 & 0.030 & 11.8 & 5.9 \\
0.77 L ha ${ }^{-1}$ & & & & & \\
April Flower [count] & & & & \\
UTC & 3 & 120 & & 3.3 & 1.9 \\
iH026a & 3 & 137 & 0.037 & 9.1 & 5.3 \\
0.77 L ha ${ }^{-1}$ & & & & & \\
Estimated yield [kg] & & & & \\
UTC & 4 & 1.3 & & 0.28 & 0.14 \\
iH026a & 4 & 1.9 & 0.017 & 0.45 & 0.22 \\
0.77 L ha ${ }^{-1}$ & & & & & \\
Colored fruit [count] & & & & \\
$\begin{array}{l}\text { UTC } \\
\text { iH026a }\end{array}$ & 4 & 174 & & 48.3 & 24.2 \\
\hline
\end{tabular}

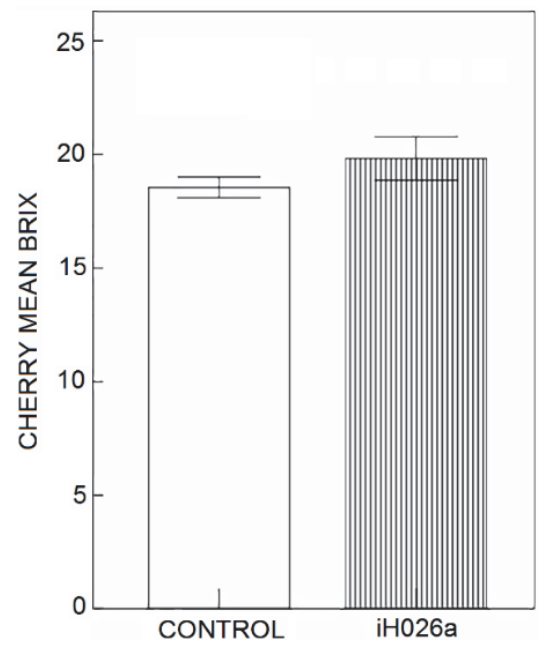

Fig. 4. Cherry trees treated with $0.77 \mathrm{~L}(\mathrm{iH} 026 \mathrm{a}) \mathrm{ha}^{-1}$ showed 95CI error bars of significantly (SD 1.14, SE 0.40) higher fruit mean Brix 19.8\%, as compared to control (SD 0.54, SE 0.19) fruit mean Brix 18.6\%. $(n=8 ; p=0.014)$.

Treatments of cherry trees with $0.77 \mathrm{~L}(\mathrm{iH} 026 \mathrm{a}) \mathrm{ha}^{-1}$ resulted in significantly $(n=4, p=0.017)$ higher estimated mean of $1.9 \mathrm{~kg}$ per tree yield than UTC estimated mean of $1.3 \mathrm{~kg}$ per tree yield. Furthermore, treatments with 0.77 $\mathrm{L}(\mathrm{iH} 026 \mathrm{a}) \mathrm{ha}^{-1}$ resulted in significantly $(\mathrm{n}=4, p=0.012)$ higher colored fruit 255 mean counts at the first pick date as compared to UTC colored fruit 174 mean counts.

The soluble sugars fraction of the harvest mass yield per cherry tree after treatment with $0.77 \mathrm{~L}(\mathrm{iH} 026 \mathrm{a}) \mathrm{ha}^{-1}$ 
resulted in $0.38 \mathrm{~kg}$ (soluble sugars) per tree as compared to UTC yield of $0.24 \mathrm{~kg}$ (soluble sugars) per tree. Therefore, treatment of cherry trees with $0.77 \mathrm{~L}(\mathrm{iH} 026 \mathrm{a}) \mathrm{ha}^{-1}$ resulted in both improved fruit flavor quality and sugar quantity.

\section{Discussion}

Source activity of photosynthesis, source-sink allocation, distribution, and contents of sugars are temporally and spatially regulated in crop plants, while sucrose and glucose dominate regulation of sugar-mediated plant growth (Ceusters et al. 2016). The preferential expression of lectins in sugar storage structures of plants - up to $10 \%$ total protein content (Lanoo et al. 2007) - portends further elucidation of roles of this biochemistry for growth regulation in seeds, shoots, fruits, and roots. The ubiquitous presence of lectins across the plant kingdom is consistent with the broad responses of dicotyledons and monocotyledons to specific exogenous glycosides (Benson et al. 2009, Biel et al. 2010). Binding specificity and affinity of lectins may correspond to the potent effect of iH026a, formulated to maintain the binding structure of lectins, leading to heightened plant quality and quantity. Methyl-ß-D-glucopyranoside remains intact (Aubert et al.

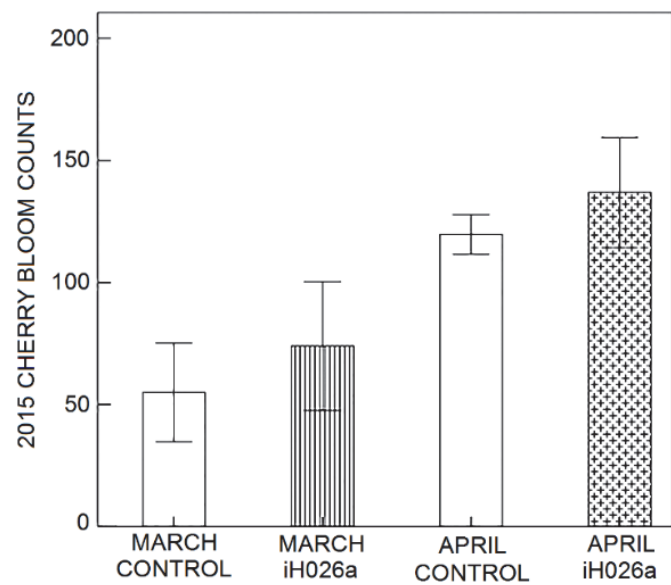

Fig. 5. Sweet cherry trees given foliar treatments of 0.77 L(iH026a) ha ${ }^{-1}$ in 2015, showed significantly (24 March, $n=4$, SD 11.8, SE 5.9, $p=0.030 ; 17$ April, $n=3$, SD 9.1, SE 5.3, $p=0.037$ ) higher mean flower counts, 24 March, 78 flowers and 17 April, 137 flowers (crosshatch bars); as compared to control mean flower counts, 24 March, 58 flowers (SD 8.3, SE 4.2 ) and 17 April, 120 flowers (SD 3.3, SE 1.9) (clear bars).
2004) at constant concentrations in plant cells (Biel et al. 2010) and assays of compounds with higher binding affinities and higher binding specificities for lectins than ß-anomers (see, for example Nonomura et al. 2012) may have contributed to improved activity of the PGR. These binding characteristics are consistent with previous results of experiments on treatment of radish seeds with formulations comprised of $\alpha$-anomers that resulted in accelerated germination (Nonomura and Benson 2014).

It is clear that plant responses to treatments with iH026a are tied to plant species, timing of applications, and dosage. For example, raisin grapes showed either enhanced Brix at high dose of iH026a or a corresponding increase of soluble sugar masss at low dose of iH026a; yet, after melons were treated with iH026a, they showed both increased Brix and greater yield than controls. In addition, stress and environmental factors may be important factors, thus, further laboratory and field investigations are being undertaken on a wide variety of food and ornamental crops in crop programs, particularly with regards to photosynthetic and respiratory systems that may improve qualities and quantities of harvests. To be true to consideration of benefits to growers and consumers, improved flowering counts such as those that we observed after treatment of cherry trees may be beneficial to florals and landscape ornamentals in the Rosaceae; while enhanced flavor and yields similar to those of the present investigation may benefit growers of other plant families. Increased soluble sugar content of plants after treatment with iH026a PGR as compared to controls supported the mechanism of action by modulation of glycoconjugates. Furthermore, greater soluble sugars in fruits of treated plants as compared to controls indicated improved flavor characteristics of the harvests. Therefore, plant development and productivity benefited from crop treatments with $\mathrm{iH} 026 \mathrm{a}$, leading to the conclusion that there is clear potential for adaptation in agriculture (Fomina and Biel 2016) by means of a wide variety of applications in plant biology (Nonomura et al. 2009, 2012; Nonomura and Benson 2013).

Open Access This article is distributed under the terms of the Creative Commons Attribution License which permits any use, distribution, and reproduction in any medium, provided the original author(s) and the source are credited.

\section{References}

Aubert S., Choler P., Pratt J. et al.: Methyl- $\beta$-D-glucopyranoside in higher plants: accumulation and intracellular localization in Geum montanum L. leaves and in model systems studied by ${ }^{13} \mathrm{C}$ nuclear magnetic resonance. - J. Exp. Bot. 55: 2179-2189, 2004.
Benson A.A., Nonomura A.M., Gerard V.A.: The path of carbon in photosynthesis. XXV. Plant and algal growth responses to glycopyranosides. - J. Plant Nutr. 32: 1185-1200, 2009.

Biel K.Y., Nonomura A.M., Benson A.A., Nishio J.N.: The path of carbon in photosynthesis. XXVI. Uptake and transport of 
methylglucopyranoside throughout plants. - J. Plant Nutr. 33: 902-913, 2010.

Biel K., Fomina I.R.: Benson-Bassham-Calvin cycle contribution to the organic life on our planet. - Photosynthetica 53: 161-167, 2015.

Christensen L.P., Peacock W.L.: Harvesting and handling - In: Raisin Production Manual. Agricultural and Natural Resources Publication 3393. Pp. 193-206. University of California, Oakland 2000.

Ceusters N., van den Ende W., Ceusters J.: Exploration of sweet immunity to enhance abiotic stress tolerance in plants: lessons from CAM. - In: Canovas F.M., Lüttge U., Matysse R. (ed.): Progress in Botany, Ed. 78. Pp. 145-166. Springer International Publishing, Zurich 2016.

Fomina I.R., Biel K.Y.: Photosynthetic carbon metabolism: strategy of adaptation over evolutionary history. - In: Allakhverdiev S.I. (ed.): Photosynthesis: New Approaches to the Molecular, Cellular, and Organismal Levels. Pp. 233-326. Scrivener Publishing, LLC, Austin 2016.

Govindjee, Shevela D., Björn L.O.: Evolution of the Z-scheme of photosynthesis: a perspective. - Photosynth Res. doi: 10.1007/s11120-016-0333-z, 2017.

Lannoo N., Vandenborre G., Miersch O. et al.: The jasmonateinduced expression of the Nicotiana tabacum leaf lectin. Plant Cell Physiol. 48: 1207-1218, 2007.
Lichtenthaler H.K., Buchanan B.B., Douce R., Govindjee: Andrew A. Benson, 1917-2015. - Photosynth. Res. 124: 131135, 2015.

Nonomura A.M., Benson A.A.: The path of carbon in photosynthesis. XXIX. Glass microbeads. - J. Plant Nutr. 35: 18961909, 2012

Nonomura A.M., Benson A.A.: The path of carbon in photosynthesis. XXX. $\alpha$-Mannosides - In: Dubinsky Z. (ed.): Photosynthesis. Pp. 3-22. InTech, Rijeka 2013.

Nonomura A.M., Benson A.A.: The path of carbon in photosynthesis. XXXI. The role of lectins. - J. Plant Nutr. 37: 785-794, 2014.

Nonomura A.M., Benson A.A., Biel K.Y.: The path of carbon in photosynthesis. XXVII. Sugar-conjugated plant growth regulators enhance general productivity. - J. Plant Nutr. 34: 653-664, 2011.

Nonomura A.M., Cullen B.A., A.A. Benson.: The path of carbon in photosynthesis. XXVIII. Responses of plants to polyalkylglycopyranose and polyacylglycopyranose - In: Najafpour M.M. (ed.): Advances in Photosynthesis Fundamental Aspects, Part 3, Chapter 13, The Path of Carbon in Photosynthesis. Pp. 259-271. InTech, Rijeka 2012.

Nonomura A., Lorimer G., Holtz B. et al.: Andrew A. Benson: Personal recollections. - Photosynth. Res. 127: 369-378, 2016. 